\title{
Vibration Energy Harvesting of Multifunctional Carbon Fibre Composite Laminate Structures
}

\author{
A. Alsaadi ${ }^{\mathrm{a}}$, Yu Shi ${ }^{\mathrm{a}, *}$, Lei $\mathrm{Pan}^{\mathrm{b}}, \mathrm{Jie}^{\mathrm{Ta}}{ }^{\mathrm{b}}, \mathrm{Yu} \mathrm{Jia}^{\mathrm{a}, *}$ \\ ${ }^{a}$ Department of Mechanical Engineering, University of Chester, Chester, CH2 4NU, United \\ Kingdom \\ ${ }^{b}$ College of Material Science and Technology, Nanjing University of Aeronautics and \\ Astronautics, Nanjing 210016, China
}

\begin{abstract}
A sustainable power supply for a wide range of applications, such as powering sensors for structural health monitoring and wireless sensor nodes for data transmission and communication used in unmanned air vehicles, automobiles, renewable energy sectors, and smart city technologies, is targeted. This paper presents an experimental and numerical study that describes an innovative technique to harvest energy resulted from environmental vibrations. A piezoelectric energy harvester was integrated onto a carbon fibre reinforced polymer (CFRP) laminate structure using the co-curing method. The integrated composite with the energy harvester was lightweight, flexible and provided robust and reliable energy outcomes, which can be used to power different low-powered wireless sensing nodes. A normalised power density of $97 \mu \mathrm{W} \mathrm{cm}{ }^{-3} \mathrm{~m}^{-2} \mathrm{~s}^{4}$ was obtained from resonance frequency of $46 \mathrm{~Hz}$ sinusoidal waves at ampitlude of $0.2 \mathrm{~g}$; while the representative environmental vibration waves in various applications (aerospace, automotive, machine and bridge infrastructure) were experimentally and numerically investigated to find out the energy that can be harvested by such a multifunctional composite structure. The results showed the energy harvested at different vibration input from various industrial sectors could be sufficient to power an autonomous structural health monitoring system
\end{abstract}

\footnotetext{
${ }^{*}$ Corresponding authors

Email addresses: y.shi@chester.ac.uk (Yu Shi), yu.jia.gb@ieee.org (Yu Jia)
}

Preprint submitted to Composites Science and Technology 
and wireless communications by the designed composite structure.

Keywords: Vibration energy harvesting, macro fibre composite, multifunctional composite, aerospace, automotive, infrastructure, compressor

\section{Introduction}

There has been a growing interest to develop multifunctional composite materials, where the actuators, sensors, controllers, and power generators can be embodied in a new smart composite structure [1, 2]. In particular, the com5 posite with capability of energy harvesting technologies has arisen a significant interest in wireless structural health monitoring technologies [3]. Various standalone vibration energy harvesters are reported, including electromagnetic vibration energy harvesters [4, 5], electrostatic vibration energy harvesters [6, 7, piezoelectric vibration energy harvesters [8, 9], and recently developed triboelectric nano-generator for vibration energy harvesting [10, 11, 12. However, the application of different energy harvesting systems depend on the specific requirement, i.e. environmental conditions and physical constraints. For instance, the efficiency of an electromagnetic vibration energy harvester drops when it is scaled-down since the number of coil turns decrease; this is a se15 ries shortcoming since in many applications there is a limited space that can be used to install a harvester [13. Electrostatic generators might be ideal for micro-applications since the gap required between capacitor plates should be small. Thus, the power outputs of electrostatic vibration energy harvesting is lower in magnitude [14.

Piezoelectric vibration energy harvesters can offer great benefits to different engineering applications due to the characteristics of mechanical and electrical energy conversion mechanism [15]. The optimal power outputs can be reflected by the load/displacement applied at a specific industrial scenario [16. In table 1. a comparison of various energy harvesting systems is shown in terms of the 25 power per unit volume. It can be seen the piezoelectric vibration energy harvest- 
ing is capable to achieve highest energy density and therefore the piezoelectric harvester was selected in this work [17, 18, 19, 20]. Considering the application for aerospace or automotive where streamlined structure was primary, the macro-fibre composite (MFC) has been able to offer structural flexibility without sacrificing charge constant and electromechanical coupling [21]. The high efficiency and almost ignorable thickness are thought to be the most ideal for integration with aircraft wing, vehicle structural body or wind turbine blade etc. The MFC was hence applied in this work to integration with CFRP.

Table 1: Comparing energy densities between three major energy harvesting mechanisms [22].

\begin{tabular}{ccccc}
\hline & Electromagnetic & Electrostatic & Piezoelectric & $\begin{array}{c}\text { Triboelectric } \\
\text { nano-generator }\end{array}$ \\
\hline Energy density & $24.8 \mathrm{~m} \mathrm{~J} \mathrm{~cm}^{-3}$ & $4 \mathrm{~m} \mathrm{~J} \mathrm{~cm}^{-3}$ & $35.4 \mathrm{~m} \mathrm{~J} \mathrm{~cm}^{-3}$ & $55 \mathrm{~m} \mathrm{~J} \mathrm{~cm}^{-3}$ \\
\hline Assumption & $\begin{array}{c}0.25 \mathrm{~T} \mathrm{magnetic} \\
\text { field }\end{array}$ & $\begin{array}{c}3 \times 10^{7} \mathrm{~V} \mathrm{~m}^{-1} \\
\text { electric field }\end{array}$ & $\begin{array}{c}\text { PZT } 5 \mathrm{H} \\
\text { material }\end{array}$ & $\begin{array}{c}\text { Liquid } \\
\text { electrode [23] }\end{array}$ \\
\hline
\end{tabular}

Energy harvesting has been studied extensively [24, 25], however, most work was published uses a typical input of sinusoidal vibration waves and few publications look at the actual representative environment data. In particular, the multifunctional composite materials combined with energy harvesting capability were rarely studied considering the various applications, such as aerospace, automotive, energy, and infrastructure applications. A recommended guide re-

40 ferring to the actual input data of above sectors should accelerate the application of energy harvesting with composite structures. Therefore, this work will be the catalyst to further develop the energy harvesting in the aerospace, automotive, energy, and infrastructure applications. Representative environment vibration data can validate and estimate the practically achievable power outputs for various selected applications. Therefore, the developed multifunctional composite can harvest sufficient energy to power an autonomous structural health monitoring and communication system for a real-time updating and directing purpose. 


\section{Methodology}

50

\subsection{Energy Harvester Integration}

MFC transducer M85280-P2 (Smart Materials, Germany) was laid up and co-cured with a $2 \times 2 \mathrm{~mm}$ twill weave carbon fibre reinforced polymer (CFRP) laminate (SHD Composite Materials, UK). The MFC M8528-P2 operates in $d_{31}$ mode, their operational lifetime is $\geq 10^{9}$ cycles when operating at $1 \mathrm{kV}_{p-p}$.

${ }_{55}$ Typical maximum voltage for energy harvesting application is expected to be $\approx 10$ 's V. Figure 1 shows the experimental set ups, where the MFC transducer $(85 \times 28 \times 0.3 \mathrm{~mm})$ was laid up onto a $(200 \times 60 \times 1.63 \mathrm{~mm})$ CFRP laminate. It was reported in the literature [26, 27] that the optimum piezoelectric area is $\approx 30 \%$ to $40 \%$ of a cantilever beam length near the clamped end. A small 60 circular metal pin was used to pre-define a mounting hole on the CFRP laminate panel, this mounting hole was used to install the CFRP laminate on the electrodynamic shaker. The whole combination was enveloped by a vacuum bag and then was placed in an oven to cure the CFRP laminate panel at $125^{\circ} \mathrm{C}$ in an oven. Conductive Silver Epoxy and wire bonds were used to route out the electrical connections prior to excitation.

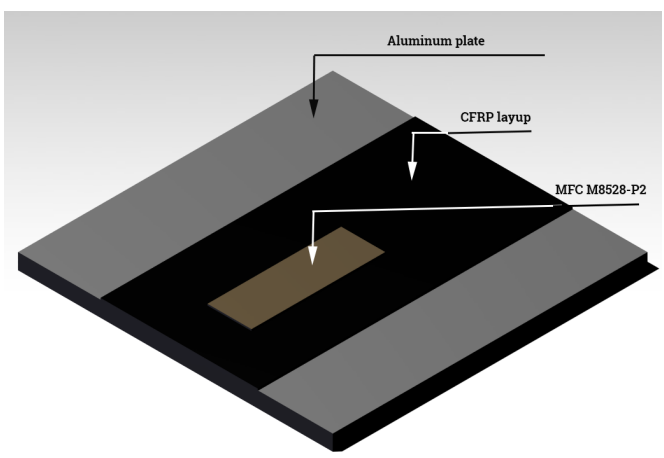

Figure 1: Schematic shows the integration process of the MFC M8528-P2 onto a CFRP laminate. 


\subsection{Excitation Method}

The MFC M8528-P2 was excited using real-life environment vibrations with an optimum load of $20 \mathrm{k} \Omega$. These vibration data were collected from different applications that were CGJ aircraft, BMW 5 series, compressor, and a suspension bridge. The frequency ranges from few hertz up to $2 \mathrm{kHz}$, while the rosonance frequency of the composite laminate at the optimum load was $46 \mathrm{~Hz}$. Waveform Editor (Agilent Technologies) was used to define and programme arbitrary waveforms on a function generator (33210A , Agilent Technologies), which in turn controlled an electrodynamic shaker (LDS 406, Brüel \& Kjaer)

75 via a power amplifier (LDS PA100E, Brüel \& Kjaer). The voltage output from the MFC M8528-P2 transducer was connected to a variable resistance box in parallel and measured by a digital oscilloscope (DSO-X-2004A, Agilent Technologies). A commercial MEMS accelerometer (ADXL 337Z, Analog Devices) was installed on the electrodynamic shaker table to replicate the actual vibration traces on the electrodynamic shake; the prototype devices and the test set up is shown in Figure 2

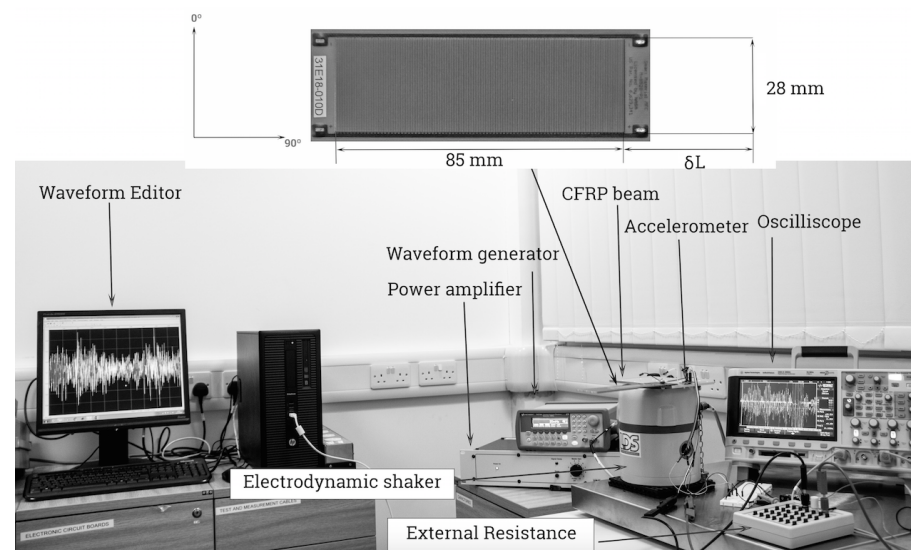

Figure 2: Experimental apparatus for the vibration characterisation of the prototype harvester. 


\section{Theory and Simulation}

\subsection{Analytical Model}

The governing equation of motion for a cantilever beam can be described by a classic beam theory, with inclusion of a viscous air damping term. The addition of a piezoelectric layer (MFC M8528-P2), a further strain rate damping term representing the electrical damping of the transducer can be included $[3]$. Therefore, the forced vibration equation of a piezoelectric cantilever beam can be described by equation 128 .

$$
E I\left(\frac{\partial^{4} w(x, t)}{\partial x^{4}}\right)+c_{s} I \frac{\partial^{5} w(x, t)}{\partial^{4} x \cdot \partial t}+c_{a} \frac{\partial w(x, t)}{\partial t}+m \frac{\partial^{2} w(x, t)}{\partial t^{2}}=F(x, t)
$$

where, $E$ is Young's modulus, $I$ is area moment of inertia, $w(x, t)$ is deflection in transverse $x$-direction, $t$ is time domain, $m$ is the effective mass of the beam, $c_{s}$ is strain rate damping coefficient and $c_{a}$ is viscous air damping coefficient. $F(x, t)$ is the excitation force, for a free vibration $F(x, t)=0$. The deflection in $\mathrm{x}$-direction $w(x, t)$ is given in 2

$$
w(x, t)=w_{b}(x, t)+w_{r e l}(x, t)
$$

With $w_{r e l}(x, t)$ as the transverse displacement relative to the clamped end of the beam and $w_{b}(x, t)$ is the base displacement. Substituting 2 in 1 and applying cantilever beam boundary conditions, the solution of the beam equation can be represented by a convergent series of eigenfunction as shown in equation 3 .

$$
w_{r e l}(x, t)=\sum_{r=1}^{\infty} \phi_{r}(x) \eta_{r}(t)
$$

Where, $\phi_{r}(x)$ and $\eta_{r}(t)$ are the mass normalised eigenfunction and the modal coordinate of a uniform clamped-free beam for the r-th mode, respectively. The natural frequency of a continuous cantilever beam can be given equation 4 .

$$
f=A \sqrt{\frac{E I}{\mu L^{4}}}
$$

Where $\mathrm{A}$ is a constant, $\mu$ is mass per unit length of the beam. The strain at a certain place on the beam at a distance $\mathrm{x}$ from the neutral axis is presented by 
equation 5

$$
\epsilon(x, t)=-x(t) \frac{\partial^{2} w}{\partial x^{2}}
$$

Furthermore, stress can be given by $\sigma(x, t)=E \epsilon(x, t)$. For a piezoelectric transducer with charge constant $d_{31}$, width $b$ and length $l$, the short circuit electrical charge $Q_{s c}$ generated from the transducer can be given by equation 6 .

$$
Q_{s c}(x, t)=d_{31} \sigma(x, t) b l
$$

Taking the total charge generated across an average stress $\sigma(t)$, the output power $P(t)$ of the piezoelectric transducer across an impedance load can then be expressed by equation 7

$$
P(t)=\left[\omega(t) d_{31} \sigma(t) b l\right]^{2} \frac{Z_{\text {load }} Z_{i}^{2}}{Z_{i}^{2}+Z_{\text {load }}^{2}}
$$

\subsection{Finite Element Analysis}

A 3D FEA model is developed and previously published as shown in figure 3 , for detailed information see [28]. The CFRP beam was made from eight plies of RC200T woven fabric CFRP; the CFRP beam was configured to a cantilever structure. Solid Mechanics, Electrostatics and Electrical Circuit physics modules within COMSOL Multiphysics were used to simulate the mechanical and piezoelectric response of the device. The beam was defined as an orthotropic material as part of the Solid Mechanics physics, with material properties presented in Table2, the mechanical properties of MFC is presented in Table 3 and Table4 for more details about electrical properties and FE model details can be found in $[28$.

Table 2: Mechanical properties of CFRP laminate

\begin{tabular}{ccccccccc}
\hline$E_{x}(\mathrm{Gpa})$ & $E_{y}(\mathrm{Gpa})$ & $E_{z}(\mathrm{Gpa})$ & $G_{x y}(\mathrm{Gpa})$ & $G_{y z}(\mathrm{Gpa})$ & $G_{x z}(\mathrm{Gpa})$ & $\nu_{x y}$ & $\nu_{y z}$ & $\nu_{x z}$ \\
\hline 59.45 & 69.3 & 3.9 & 62.9 & 1.5 & 62.35 & 0.3 & 0.4 & 0.3 \\
\hline
\end{tabular}

Eigenfrequency analysis revealed natural frequency at $47.2 \mathrm{~Hz}\left(1^{\text {st }}\right.$ bending mode), with the first few higher resonant modes estimated at: $147.1 \mathrm{~Hz}\left(1^{\text {st }}\right.$ lateral mode), $275.4 \mathrm{~Hz}$ ( $2^{\text {nd }}$ bending mode), $362.3 \mathrm{~Hz}$ ( $1^{\text {st }}$ torsional mode), $772.0 \mathrm{~Hz}$ 
Table 3: Mechanical properties of MFC 21]

\begin{tabular}{cccccc}
\hline$E_{1}(\mathrm{Gpa})$ & $E_{1}(\mathrm{Gpa})$ & $G_{12}(\mathrm{Gpa})$ & $\nu_{12}$ & $\nu_{21}$ & $\rho\left(\mathrm{kg} \cdot \mathrm{m}^{-3}\right)$ \\
\hline 30.34 & 15.86 & 5.52 & 0.31 & 0.16 & 5400 \\
\hline
\end{tabular}

Table 4: Piezoelectric and dielectric properties 21]

\begin{tabular}{ccccc}
\hline$d_{31}(p C / N)$ & $d_{33}(p C / N)$ & $C\left(n F / c^{2}\right)$ & $\epsilon_{p}(n F / m)$ & $\epsilon_{r}$ \\
\hline-170 & 400 & 7.8 & 0.15 & 1695 \\
\hline
\end{tabular}

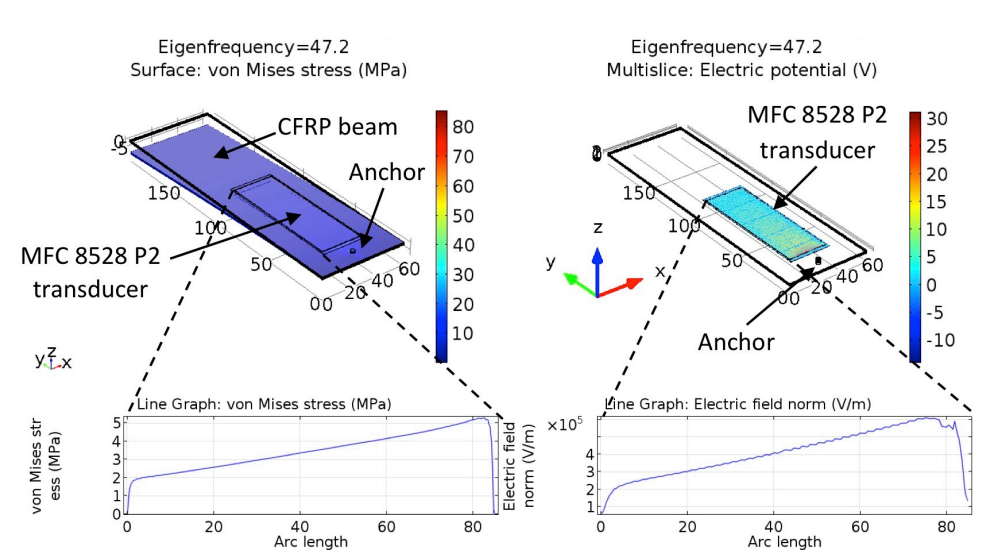

Figure 3: FE model of the MFC-on-composite vibration energy harvester. The natural frequency is at $47.2 \mathrm{~Hz}$. The figures on the left shows the stress induced while the figures on the right illustrates the generated voltage. This is the region near the clamped end of the beam where stress induced electric charge is most profitable.

( $3^{\text {rd }}$ bending mode), $1095.2 \mathrm{~Hz}$ ( $2^{\text {nd }}$ torsional mode), $1498.9 \mathrm{~Hz}$ ( $4^{\text {th }}$ bending mode) and $1935.0 \mathrm{~Hz}$ ( $3^{\text {rd }}$ torsional mode). Body load was used to introduce base point acceleration for Frequency Domain and Time Dependent Modal analyses. Damping ratio of 0.02 was used as a starting assumption, and fitted according to experimentally measured quality factor. 


\section{Results and Discussions}

\subsection{Sinusoidal Vibration Waves}

105

The average power responses at the different acceleration input was compared in Figure 4. The energy harvested was remarkably increased with the higher acceleration introduced. It could be also found the peak of energy that can be harvested always occurred at a consistent frequency value of $46 \mathrm{~Hz}$, which is barely related to the acceleration applied. Figure 5 showed that RMS voltage outputs were typically in the order of a few 1's volts, even for a broadband noise excitation. This is ideal for overcoming the minimum diode or transistor voltage thresholds to activate conditioning and power management circuits. The

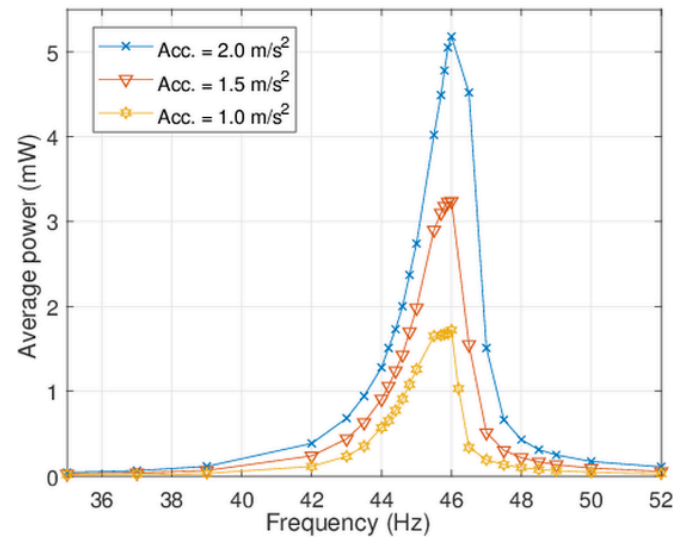

Figure 4: Changes in power outcomes at sinusoidal frequencies of $33 \mathrm{~Hz}$ to $52 \mathrm{~Hz}$ at various accelerations with a resistive load of $20 \mathrm{k} \Omega$.

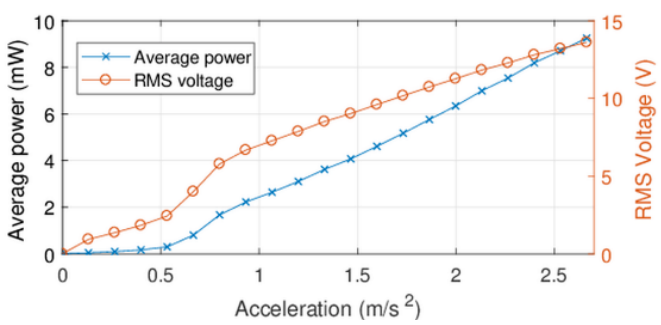

Figure 5: Average power outputs at resonant frequency of $46 \mathrm{~Hz}$ with a resistive load of $20 \mathrm{k} \Omega$. 
highest average power recorded was $9.25 \mathrm{~mW}$ at vibration level of $2.66 \mathrm{~m} \mathrm{~s}^{-2}$ under frequency of $46 \mathrm{~Hz}$, in Figure 5 Higher acceleration scan was not done due to experimental constraints. Given a total volume of $13.5 \mathrm{~cm}^{3}$, the power density normalised against acceleration squared is $97 \mu \mathrm{W} \mathrm{cm}{ }^{-3} \mathrm{~m}^{-2} \mathrm{~s}^{4}$, which compares favourably against some of the state-of-the-art in the literature, such as a thinned bulk PZT harvester at $105 \mu \mathrm{W} \mathrm{cm}{ }^{-3} \mathrm{~m}^{-2} \mathrm{~s}^{4}[29$. Similar work was undertaken by other researchers, as presented in Table 5. However, lower power densities were obtained as shown in the table. The high power density obtained in this work was attributed to many factors, such as in a previous study finds that integrating MFC M8482-P2 harverster with CFRP laminate using co-curing method helps to avoid any additional dissipation of energy as well as allows the harvester to yield a direct image of strain/displacement within CFRP laminate beam [30]. The second factor was the optimised position of the harvester on the cantilever structure, a previous study suggests that to optimise energy output the harvester should be placed $30 \%$ - $40 \%$ away from the clamped end 26. In addition, the MFC co-cured composite offers the benefit of flexibility to be compatible with streamlined structure and the resin from carbon fibre prepreg forms the protection outside the MFC to resist externally environmental and operational impact during application.

Table 5: Comparison of power density for various piezoelectric energy harvesters from sinusoidal waves.

\begin{tabular}{cccc}
\hline Frequency $(\mathrm{Hz})$ & Amplitude $(\mathrm{g})$ & Power density $\left(\mathrm{mWcm}^{-3}\right)$ & Reference \\
\hline 100 & 7.2 & 82 & 31 \\
\hline 120.1 & 0.4 & 0.0932 & 32 \\
\hline 5 & 0.21 & 2.255 & 33 \\
\hline
\end{tabular}

\subsection{Aerospace Vibration Waves}

The vibration data used in this study was collected from CGJ aircraft, where the vibration was dominated by an internal mechanical sources. However, due to the vibration of the body (external source) and the aero-engine (internal source) 
while in-flight, the vibration data was typically broadband and high frequency in nature $(\approx 2 \mathrm{kHz})$ with some periodic frequency signatures embedded [34]. The amplitudes of these vibration waves can potentially attain severals 10's of g. Figure 6a shows a typical example of the broadband vibration (x-axis rans along the aircraft) in-flight. The Fast Fourier Transform (FFT) analysis revealed that there was not a dominant frequency peak and it was a band-limited noise vibration, as shown in Figure 6 b.
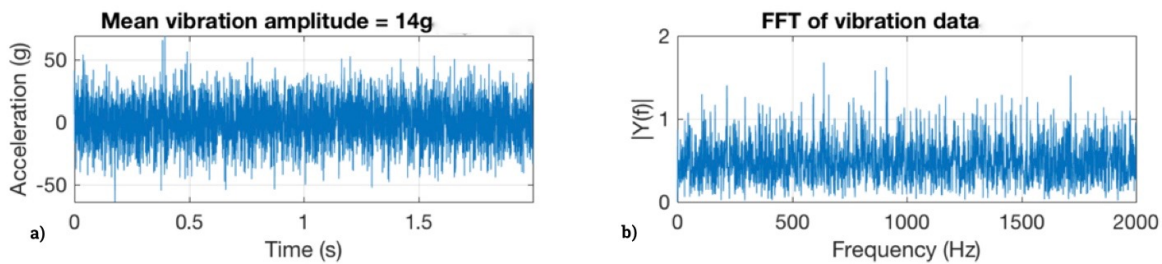

Figure 6: CGJ vibration trace of x-axis 34 in a) time series data and b) FFT analysis. The mean vibration amplitude was $14 \mathrm{~g}$.

The average vibration amplitude was around $14 \mathrm{~g}$, while the maximum peak to peak values exceeded $100 \mathrm{~g}$. It was not possible to replicate the full amplitude range of this trace using the available laboratory electrodynamic shaker system, as described in Section 2.2. Experimental measurements were therefore taken up to $1.8 \mathrm{~g}$ average amplitude (over $10 \mathrm{~g}$ peak to peak). Using measured results, a power fit was performed to estimate the power outcomes of input vibration trace up to the full amplitude range was applied (figure 7). During the elevation

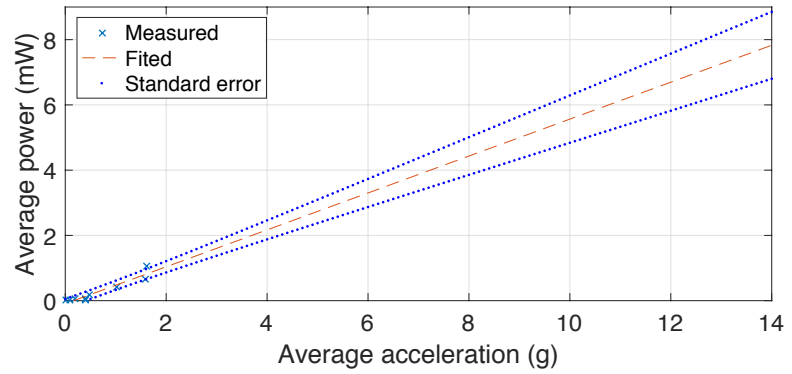

Figure 7: Experimentally measured power response for CGJ aircraft along x-axis vibration trace. 
flight data on the other hand, continuously varying periodic frequency signatures started to emerge amongst the broadband vibration. This was contributed in part by the aero-engine. Figure 8 illustrates an example of such a vibration trace at $\mathrm{y}$-axis and z-axis for CGJ type aircrafts, y-axis ran across while z-axis ran up through the aircraft. The average amplitude varies between $5 \mathrm{~g}$ to over $7 \mathrm{~g}$ across various axes. Figure 9 presents the experimentally measured average
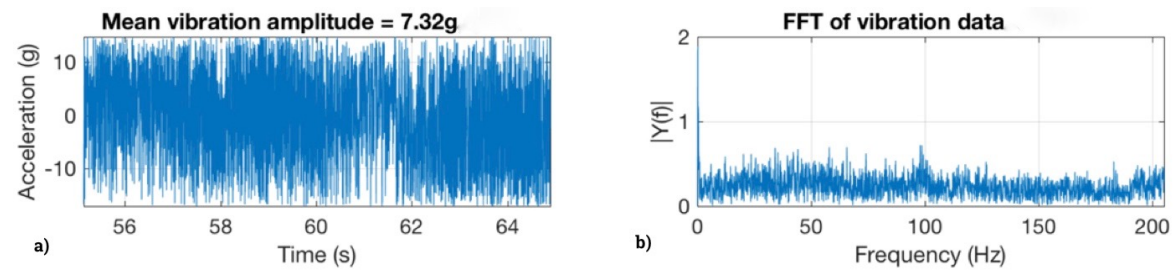

(a) Y-axis
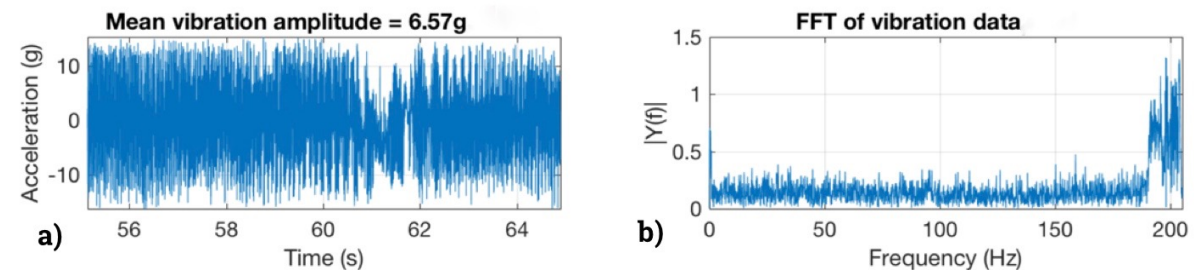

(b) Z-axis

Figure 8: CGJ vibration trace y-axis and z-axis [34 in a) time series data and b) FFT analysis. The vibration amplitudes were $7.32 \mathrm{~g}$ and $6.57 \mathrm{~g}$ in $\mathrm{y}$-axis and $\mathrm{z}$-axis respectively.

power outputs when the prototype device was subjected to the elevation flight data of CGJ type aircraft. Experimental measurements were taken up to $2.8 \mathrm{~g}$ and numerical fit was applied to over $7 \mathrm{~g}$. Three axes data were separately ran on an electrodynamic shaker and power outcomes measured in turn. In real applications, all three axes vibrations would be simultaneously experienced by the harvester. However, the experimental apparatus adopted in this study can only characterise one axis at a time. The maximum in-flight power density obtained was $0.077 \mathrm{~mW} \mathrm{~cm}^{-3}$ at vibration amplitude of $1.6 \mathrm{~g}$ and $0.577 \mathrm{~mW} \mathrm{~cm}^{-3}$ at vibration amplitude of $14 \mathrm{~g}$. At a given acceleration that amount of energy was low when it was compared with commercial harvesters, such as APA400M-MD 
(CEDRAT technologies,France) and PVEH (MicroStrain,USA) that can harvest up to $1.42 \mathrm{~mW} \mathrm{~cm}^{-3}$ and $0.46 \mathrm{~mW} \mathrm{~cm}^{-3}$ when excited at resonance frequency of $100 \mathrm{~Hz}$ and $1000 \mathrm{~Hz}$ (at vibration amplitude $1.5 \mathrm{~g}$ ) respectively. The current vibration energy harvester has advantages over APA400M-MD and PVEH that it was low profile, highly flexible, and smaller in size $13.5 \mathrm{~cm}^{3}$ where APA400M$\mathrm{MD}$ and PVEH are $35.2 \mathrm{~cm}^{3}$ and $64 \mathrm{~cm}^{3}$ respectively.

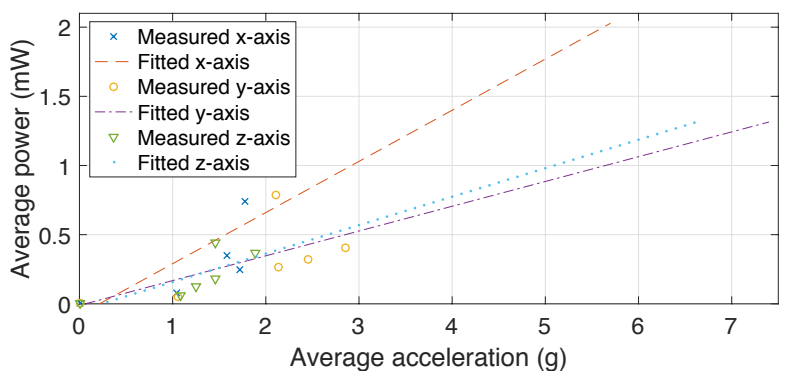

Figure 9: Experimentally measured and fitted power response for $y$-axis and z-axis CGJ aircraft vibration trace.

\subsection{Automotive Vibration Waves}

The automotive industry has an immense interest in energy harvesting to self-power wireless sensor systems for control and safety purposes as well as V2X concept and therefore avoid the weight and assembly difficulties resulted from cable/wire connections. Moreover, it is also promising to help assess the safety of battery by efficient self-powered monitoring systems. Although high amount of energy can be recovered from suspension or brake systems in most of road cars, the current study is interested in harvesting power from low frequency and acceleration sources for powering sensors and wireless nodes. Figure 10 presents vibration data measured from under the bonnet of a road car near its engine, the axes were set as following: $\mathrm{x}$-axis ran along the car, $\mathrm{y}$-axis ran across the car, and z-axis ran up through the car. The road car used in this study was a BMW 525D SE 2011 model. X-axis vibration (mean amplitude $0.68 \mathrm{~g}$ ) contained a clear frequency peak at around $33 \mathrm{~Hz}$ corresponding to the engine's $2000 \mathrm{RPM}$, followed by two harmonics at twice and thrice the frequency. As the RPM 
of the engine varied when the accelerator was engaged, these frequency peaks also varied. Z-axis vibration (mean amplitude $1.05 \mathrm{~g}$ ) was more broadband, with a flat active frequency range covering up to the first $200 \mathrm{~Hz}$, suggesting a combination of various structural responses and their harmonics. Y-axis was a combination of the two frequency characteristics with a mean amplitude of $0.86 \mathrm{~g}$. It was noticed that the vibration data in the three axes depended on many factors such as, the roughness of the roads, the health condition of the car and the acceleration.
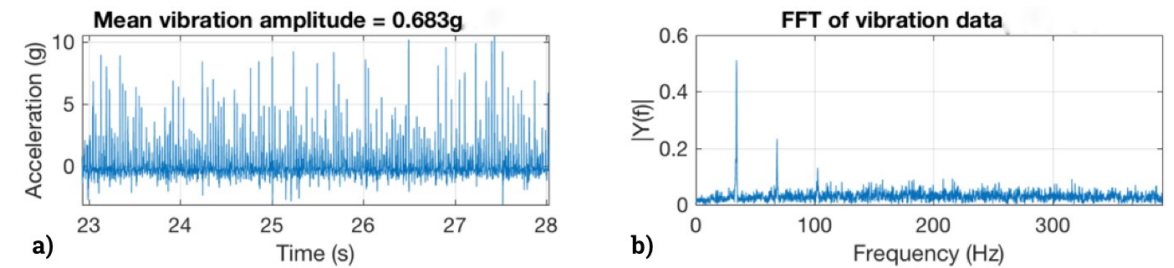

(a) $\mathrm{X}$-axis
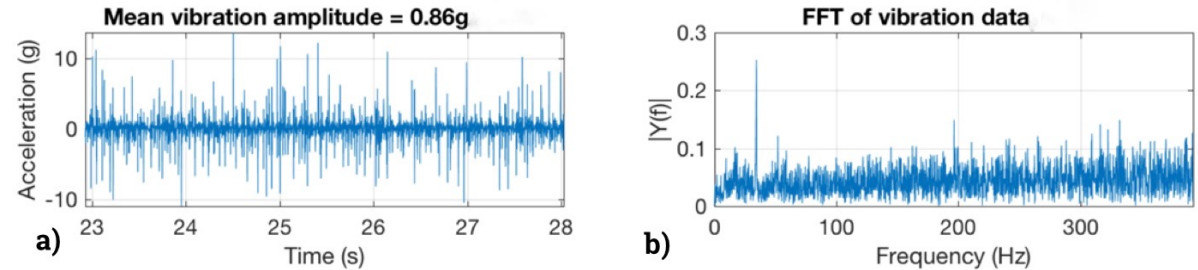

(b) Y-axis
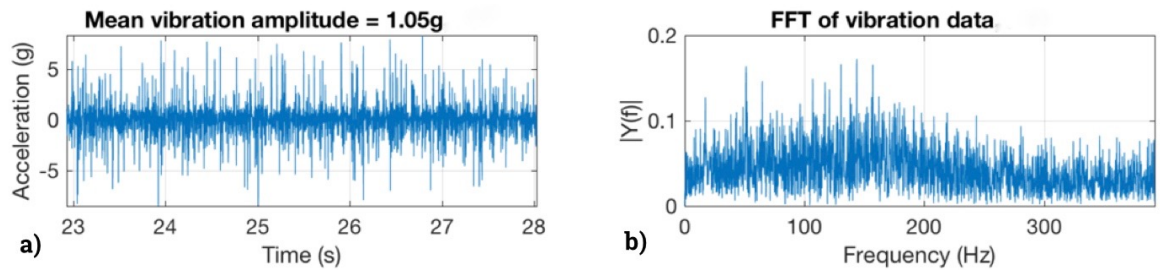

(c) Z-axis

Figure 10: Representative environment vibration of a road car near the engine beneath the bonnet, measured using GCDC vibration logger X16-4 [35. a) Time domain vibration data, b) FFT analysis.

Figure 11 summarises the average power output measured in the lab, when 
subjected to representative data testing of various axes. It can be seen that the $\mathrm{x}$ and $\mathrm{y}$ axes vibration induced the highest power response. The response was off-resonant with some level of resonant trigger from the wide active frequency region covered by z-axis vibration. in Figure 11 the measurements were taken up to $0.65 \mathrm{~g}$ within the lab and the rest of the amplitude range up to $1.0 \mathrm{~g}$ was numerically fitted as per the existing data.

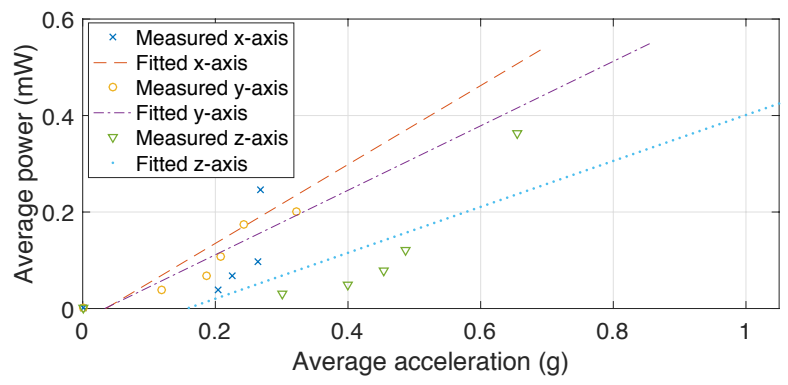

Figure 11: Experimentally measured power response of the energy harvester at varying input accelerations of the automotive vibration data.

It should be noted that the current harvester prototype natural frequency at $46 \mathrm{~Hz}$ does not match with the first frequency peak $(33 \mathrm{~Hz})$ of the $\mathrm{x}$-axis automotive representative vibration data, as shown in Figure 10. Therefore, the

frequency matched design, with the same transducer and device size, the power output was numerically estimated to be able to attain $3.5 \mathrm{~mW}$ across a load resistance of $20 \mathrm{k} \Omega$. At this average power output, there was already sufficient power budget to sustain most low power autonomous wireless sensors $\approx 0.8-$ 215 output can theoretically be substantially improved when the dimensions were designed specifically for the target frequency application. Nonetheless, even for the current experimentally measured output with the mismatched harvester, the road car representative data still managed to generate about $0.37 \mathrm{~mW}$ average power at an average acceleration amplitude of $0.25 \mathrm{~g}$. For an ideally resonance $3 \mathrm{~mW}[36$. power response was primarily non-resonant for this unmatched case. The power 


\subsection{Machine Vibration Waves}

The increased usage of composite materials in machinery encouraged to investigate the amount of power that could be harvested. For most machine and engine applications there is a distinct frequency signature associated with the

quency in the range between $0-500 \mathrm{~Hz}$. However, in the present study the use of cantilevered CFRP beam helped to increase the deformation due to vibration. This is in turn led to higher energy accumulation. 

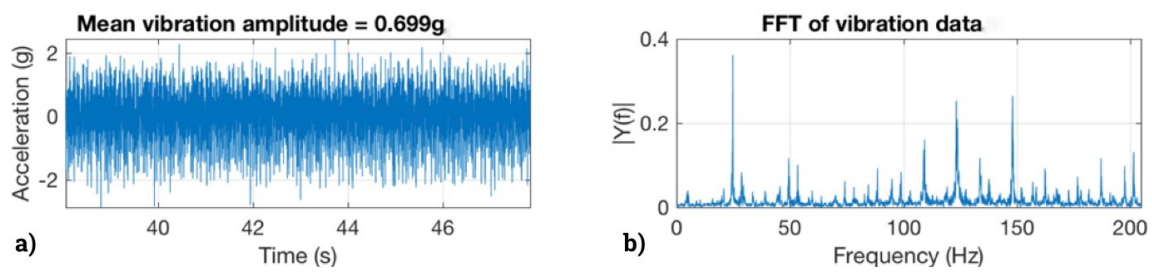

(a) X-axis
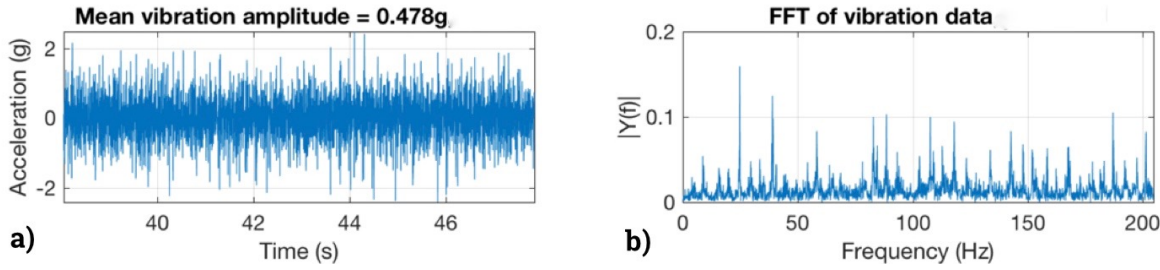

(b) Y-axis
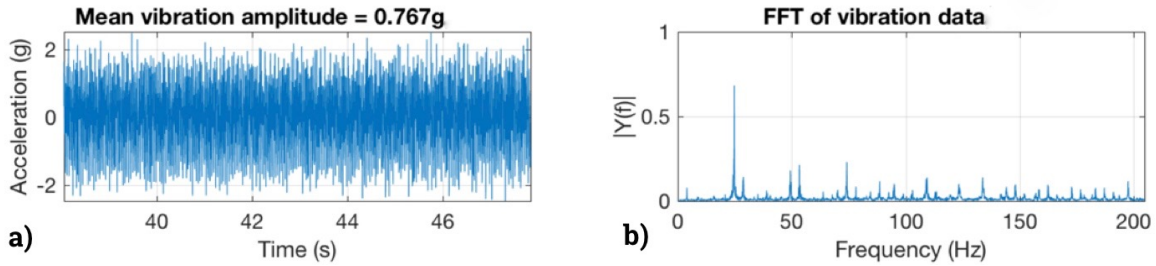

(c) Z-axis

Figure 12: Representative environment vibration of a compressor motor, measured using GCDC vibration logger X16-4 35. a) Time domain vibration data, and b) FFT analysis.

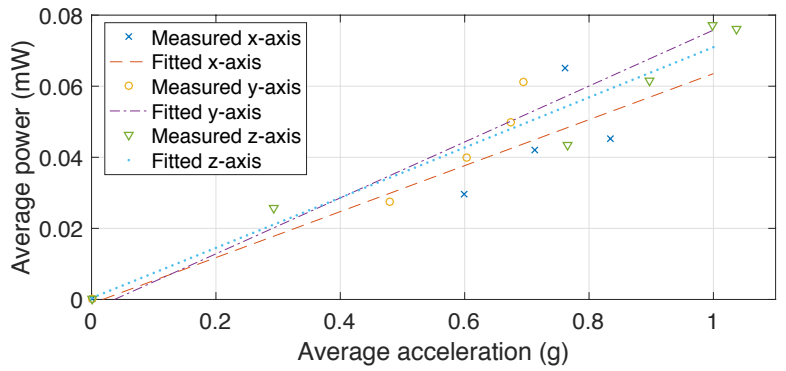

Figure 13: Experimentally measured power response across $20 \mathrm{k} \Omega$ of a resistive load for varying input acceleration of the compressor motor vibration data. 


\subsection{Bridge Vibration Waves} frastructures, such as roadway and bridges [38, 39. Composite material with the proposed integrated energy harvesting functionality can also be used in infrastructural applications, such as the body of key support structures within bridges, tunnels and rail applications. In addition to their lightweight, CFRP energy harvested in turn may be used to power and sustain embedded sensors for health monitoring of a structure or other applications. Different transducer configurations were adopted on roadways, such as cymbal piezoelectric transducer [40, the energy harvested was $1.2 \mathrm{~mW}$ at frequency of $20 \mathrm{~Hz}$ per one

power of $0.17 \mathrm{~mW}$ was measured at an average acceleration amplitude of $0.32 \mathrm{~g}$. For a matched frequency harvester design, the average power was estimated to attain $1.0 \mathrm{~mW}$. The harvested energy was $17.7 \%$ higher than the energy har- 

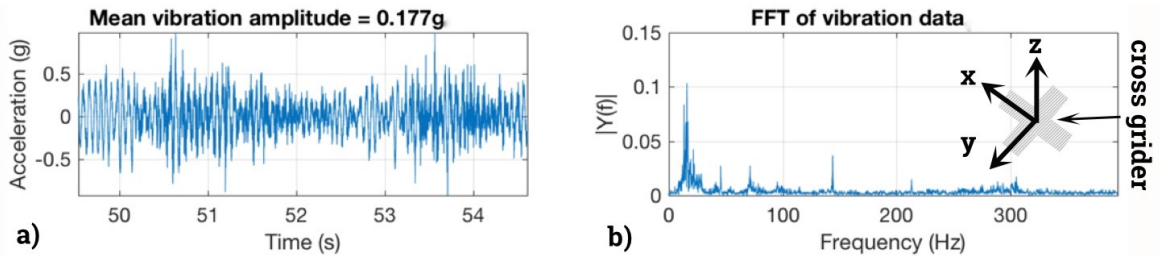

(a) X-axis
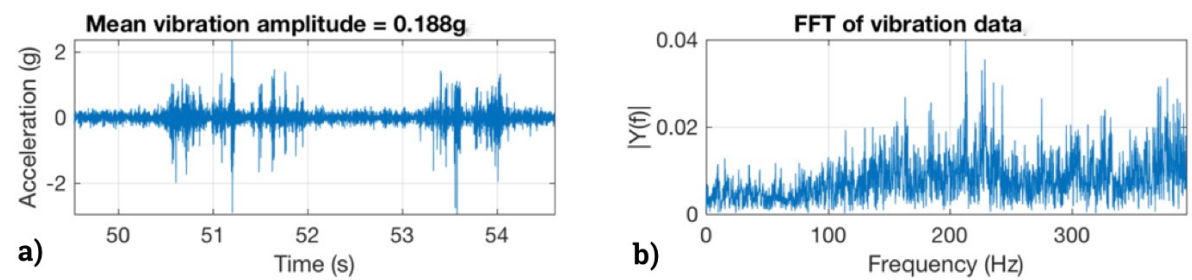

(b) Y-axis
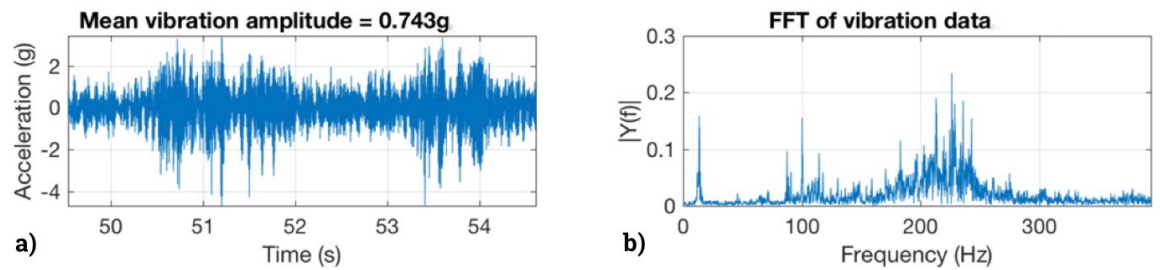

(c) Z-axis

Figure 14: Representative environment vibration for three axes of cross girder on the Forth Road Bridge (suspension bridge), measured using GCDC vibration logger X16-4 [35]. a) Time domain vibration data, b) FFT analysis.

vested from bridges due to traffic-induced vibrations as reported in [42], where a cantilevered traffic-induced energy harvester was excited at resonance of $14.5 \mathrm{~Hz}$ and vibration amplitude of $0.03 \mathrm{~ms}^{-2}$. 


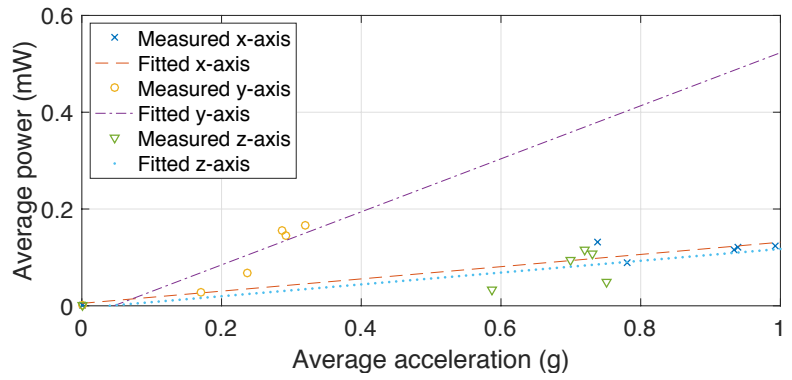

Figure 15: Experimentally measured power response measured across $20 \mathrm{k} \Omega$ load resistance for varying input acceleration of the suspension bridge vibration data.

\section{Conclusions}

The result of an extensive experimental and numerical study conducted on carbon fibre composite laminates and macro-fibre composites are presented and discussed thoroughly. Hence, this paper will be helpful resource and reference with real world vibration data for multifunctional composites with energy harvesting capability. The energy harvesting of sinusoidal, aerospace, automotive, machinery, and infrastructure vibration waves is investigated. The experimental results supported by numerical modelling indicate that relatively high-power outcomes from the thin profile and flexible harvester offers a feasible on-composite laminate power solution for microelectronics and sensors that can be similarly integrated onto the composite stack.

For sinusoidal vibration waves at resonance of $46 \mathrm{~Hz}$ and vibration amplitude of $0.27 \mathrm{~g}$, power of $0.6 \mathrm{mWcm}^{-3}$ is obtained. Power output obtain from environmental vibration waves was lower in magnitude than sinusoidal vibration waves. Environmental CGJ aircraft vibration waves yield power in the range between $0.077 \mathrm{mWcm}^{-3}$ to $0.577 \mathrm{mWcm}^{-3}$ at vibration amplitude of $1.6 \mathrm{~g}$ and $14 \mathrm{~g}$ respectively. Power harvested from environmental automotive (BMW 5 series), compressor, and a suspension bridge vibration waves are much lower than CGJ aircraft. Power outputs are $0.027 \mathrm{mWcm}^{-3}$ at frequency of $33 \mathrm{~Hz}$ and vibration amplitude of $0.25 \mathrm{~g}, 5.7 \mu \mathrm{Wcm}^{-3}$ at frequency of $26.7 \mathrm{~Hz}$ and vibration amplitude of $1 \mathrm{~g}$, and $0.012 \mathrm{mWcm}^{-3}$ at frequency of $15 \mathrm{~Hz}$ and vibration 
amplitude of $0.32 \mathrm{~g}$ respectively. It is noted that the power outcomes can be

frequencies.

\section{Acknowledgements}

This research was supported by Innovate UK (Project Reference 104030).

\section{References}

[1] K. Sairajan, G. Aglietti, K. Mani, A review of multifunctional structure technology for aerospace applications, Acta Astronautica 120 (2016) 3042.

[2] S. F. Tie, C. W. Tan, A review of energy sources and energy management system in electric vehicles, Renewable and sustainable energy reviews 20 (2013) 82-102.

[3] S. Priya, D. J. Inman, Energy harvesting technologies, Vol. 21, Springer, 2009.

[4] R. Torah, P. Glynne-Jones, M. Tudor, T. O'donnell, S. Roy, S. Beeby, Self-powered autonomous wireless sensor node using vibration energy harvesting, Measurement science and technology 19 (12) (2008) 125202.

[5] C. Williams, R. C. Woods, R. Yates, Feasibility study of a vibration powered micro-electric generator.

[6] S. Meninger, J. O. Mur-Miranda, R. Amirtharajah, A. Chandrakasan, J. H. Lang, Vibration-to-electric energy conversion, IEEE Transactions on Very Large Scale Integration (VLSI) Systems 9 (1) (2001) 64-76.

[7] W. Ma, M. Wong, L. Ruber, Dynamic simulation of an implemented electrostatic power micro-generator, in: Proc. Design, Test, Integration and Packaging of MEMS and MOEMS, 2005, pp. 380-5. 
[8] A. Erturk, D. J. Inman, Piezoelectric energy harvesting, John Wiley \& Sons, 2011.

[9] G. K. Ottman, H. F. Hofmann, A. C. Bhatt, G. A. Lesieutre, Adaptive piezoelectric energy harvesting circuit for wireless remote power supply, IEEE Transactions on power electronics 17 (5) (2002) 669-676.

[10] Z. L. Wang, Triboelectric nanogenerators as new energy technology for selfpowered systems and as active mechanical and chemical sensors, ACS nano 7 (11) (2013) 9533-9557.

[11] W. Yang, J. Chen, Q. Jing, J. Yang, X. Wen, Y. Su, G. Zhu, P. Bai, Z. L. Wang, 3d stack integrated triboelectric nanogenerator for harvesting vibration energy, Advanced Functional Materials 24 (26) (2014) 4090-4096.

[12] W. Yang, J. Chen, G. Zhu, X. Wen, P. Bai, Y. Su, Y. Lin, Z. Wang, Harvesting vibration energy by a triple-cantilever based triboelectric nanogenerator, Nano Research 6 (12) (2013) 880-886.

[13] S. P. Beeby, T. O’Donnell, Electromagnetic energy harvesting, in: Energy Harvesting Technologies, Springer, 2009, pp. 129-161.

[14] P. Basset, E. Blokhina, D. Galayko, Electrostatic kinetic energy harvesting, John Wiley \& Sons, 2016.

[15] D. Zhu, S. P. Beeby, M. J. Tudor, N. R. Harris, A credit card sized self powered smart sensor node, Sensors and Actuators A: Physical 169 (2) (2011) 317-325.

${ }_{345}[16]$ S. P. Beeby, M. J. Tudor, N. White, Energy harvesting vibration sources for microsystems applications, Measurement science and technology 17 (12) (2006) R175.

[17] O. Sosnicki, N. Lhermet, F. Claeyssen, Vibration energy harvesting in aircraft using piezoelectric actuators, in: Proc Actuator, 2006, pp. 968-971. 
[18] S. W. Arms, C. P. Townsend, D. L. Churchill, M. Augustin, D. Yeary, P. Darden, N. Phan, Tracking pitch link dynamic loads with energy harvesting wireless sensors, in: ANNUAL FORUM PROCEEDINGS-AMERICAN HELICOPTER SOCIETY, Vol. 63, AMERICAN HELICOPTER SOCIETY, INC, 2007, p. 934.

[19] P. Glynne-Jones, M. J. Tudor, S. P. Beeby, N. M. White, An electromagnetic, vibration-powered generator for intelligent sensor systems, Sensors and Actuators A: Physical 110 (1-3) (2004) 344-349.

[20] H. Sodano, G. Park, D. Inman, An investigation into the performance of macro-fiber composites for sensing and structural vibration applications, Mech. Syst. Signal Process. 18 (2004) 683-697.

[21] Macrofibre composites (mfc) - www.smart-material.com/mfc-productmain.html.

[22] Y. Jia, The convergence of parametric resonance and vibration energy harvesting, Ph.D. thesis, University of Cambridge, Cambridge, UK (2014).

[23] W. Tang, T. Jiang, F. R. Fan, A. F. Yu, C. Zhang, X. Cao, Z. L. Wang, Liquid-metal electrode for high-performance triboelectric nanogenerator at an instantaneous energy conversion efficiency of $70.6 \%$, Advanced Functional Materials 25 (24) (2015) 3718-3725.

[24] M. R. Pearson, M. J. Eaton, R. Pullin, C. A. Featherston, K. M. Holford, Energy harvesting for aerospace structural health monitoring systems, in: Journal of Physics: Conference Series, Vol. 382, IOP Publishing, 2012, p. 012025 .

[25] S. R. Anton, D. J. Inman, Vibration energy harvesting for unmanned aerial vehicles, in: Active and Passive Smart Structures and Integrated Systems 2008, Vol. 6928, International Society for Optics and Photonics, 2008, p. 692824. 
[26] S. Du, Y. Jia, A. Seshia, Maximizing output power in a cantilevered piezoelectric vibration energy harvester by electrode design, in: Journal of Physics: Conference Series, Vol. 660, IOP Publishing, 2015, p. 012114.

[32] L. Gu, Low-frequency piezoelectric energy harvesting prototype suitable for the mems implementation, Microelectronics Journal 42 (2) (2011) 277-282.

[33] K. Uchino, T. Ishii, Energy flow analysis in piezoelectric energy harvesting systems, Ferroelectrics 400 (1) (2010) 305-320.

400

[34] Do-160, environmental conditions and test procedures for airborne equipment, Tech. rep., Radio Technical Commission for Aeronautics (2010).

[35] Y. Jia, J. Yan, S. Du, T. Feng, P. Fidler, C. Middleton, K. Soga, A. A. Seshia, Real world assessment of an auto-parametric electromagnetic vibra- 
tion energy harvester, Journal of Intelligent Material Systems and Structures 29 (7) (2017) 1481-1499.

[36] R. J. Vullers, R. Van Schaijk, H. J. Visser, J. Penders, C. Van Hoof, Energy harvesting for autonomous wireless sensor networks, IEEE Solid-State Circuits Magazine 2 (2) (2010) 29-38.

[37] H. A. Sodano, G. Park, D. J. Leo, D. J. Inman, Use of piezoelectric energy harvesting devices for charging batteries, in: Smart Structures and Materials 2003: Smart Sensor Technology and Measurement Systems, Vol. 5050, International Society for Optics and Photonics, 2003, pp. 101-109.

[38] Y.-H. Shin, I. Jung, M.-S. Noh, J. H. Kim, J.-Y. Choi, S. Kim, C.-Y. Kang, Piezoelectric polymer-based roadway energy harvesting via displacement amplification module, Applied Energy 216 (2018) 741-750.

[39] H. Wang, A. Jasim, X. Chen, Energy harvesting technologies in roadway and bridge for different applications-a comprehensive review, Applied Energy 212 (2018) 1083-1094.

[40] H. Zhao, J. Yu, J. Ling, Finite element analysis of cymbal piezoelectric transducers for harvesting energy from asphalt pavement, Journal of the Ceramic Society of Japan 118 (1382) (2010) 909-915.

[41] H. Yang, L. Wang, B. Zhou, Y. Wei, Q. Zhao, A preliminary study on the highway piezoelectric power supply system, International Journal of Pavement Research and Technology 11 (2) (2018) 168-175.

${ }_{425}$ [42] M. Peigney, D. Siegert, Piezoelectric energy harvesting from traffic-induced bridge vibrations, Smart Materials and Structures 22 (9) (2013) 095019. 